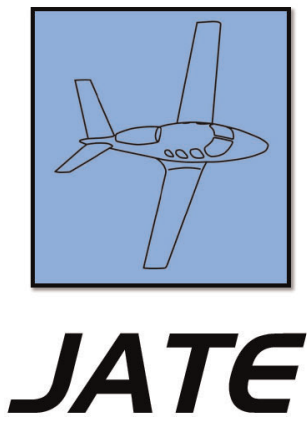

Journal of Aviation Technology and Engineering 8:2 (2019) 2-7

\title{
General Aviation Hypoxia and Reporting Statistics
}

\author{
Timothy Holt, Jacqueline Luedtke, Jennah Perry, Michelle Hight, Claire \\ Schindler, and Pamela Ward
}

Embry-Riddle Aeronautical University

\begin{abstract}
Hypoxia is defined as a lack of oxygen throughout the body, which can be caused by several factors at any altitude. General aviation (GA) pilots may argue that most GA aircraft cannot attain the required altitudes where one might be more affected by hypoxia, but it is exactly that attitude that may makes pilots more susceptible to hypoxia. The impact of this hazardous attitude is even more apparent if one considers that out of the 590,038 certificated pilots in the USA, a little over $30 \%$ of them are GA pilots (FAA, 2015). The problem is that unlike airline pilots or military pilots, there are no specific requirements for GA pilots to receive flight physiology training that could cover hypoxia causes, recognition, and recovery. Furthermore, there is no existing mandate requiring GA pilots to report episodes of hypoxia to any safety or statistics agency, such as NASA. Without reports, records, or statistics on hypoxia, there is no way to observe trends through the years, which could help prevent other GA pilots from experiencing the same hazard. To obtain more information on GA pilots' experiences with hypoxia, the Aircraft Owners and Pilots Association and Curt Lewis \& Associates, a safety forum and recommendation service for the aviation industry, distributed an anonymous survey via electronic newsletter to collect hypoxia data. Questions within this survey asked about the pilot's experience at the time, flight condition, and any previous flight physiology training he or she may have had. The information obtained was analyzed to create statistics that could show how often hypoxia occurs for GA pilots and how effective flight physiology training is for the GA population.

To this day, there are no reported statistics about GA pilots that have survived hypoxia during normal flight operations. This leaves the aviation community unsure of which circumstances pilots find themselves in that might create a hypoxic state, as well as whether or not that pilot reported the occurrence to the proper establishments. It is with this in mind that several questions arise:
\end{abstract}

1. Are GA pilots trained to recognize the effects and symptoms of hypoxia?

2. Have those that have survived hypoxic situations reported them?

3. Are the current reporting requirements satisfactory?

The GA community was the focus for this study due to the common belief that GA aircraft, usually normally aspirated single-engine aircraft, cannot attain altitudes where hypoxia is a factor. This invulnerable attitude, in combination with a lack of resources available for flight physiology training to the GA community, made this population of the aviation industry prime candidates for this study.

It should be noted that Federal Aviation Regulation 91.211 does not require pilots to use supplemental oxygen until cruising at 12,500 feet for 30 minutes or more. The training requirements for the Private Pilot Airman Certification Standards require students to understand the causes, effects, and recovery methods of hypoxia, but no further practical training is required. It should also be noted that pilots, whether commercial operators or GA, have no legal requirement to report a hypoxic event, and it is because of this that the research team believes there are no statistics on the frequency, commonality, or severity of GA hypoxia.

Keywords: hypoxia, general aviation, reporting 


\section{Literature Review}

In general, hypoxia has been less of a concern for general aviation (GA) pilots because they are under the impression that the possibility of hypoxia is not likely due to their flight at lower altitudes. However, in the study entitled Effects of mild hypoxia on pilot performances at general aviation altitudes, the authors found that perceptual-motor performance at pressure-altitude equivalents of 7,000 and 12,000 feet in a hypobaric chamber had significantly slower response times at both altitudes as compared to sea level (Nesthus, Rush, \& Wreggit, 1997). This FAAsponsored report explains that GA pilots demonstrated a significant decrease in human performance while flying at various altitudes and performing simple navigational tasks. However, the report contains no statistics regarding how often a hypoxic event might occur in GA flight operations and what flight configuration would be the most detrimental. The study accentuates the importance of understanding the effects of hypoxia on the body and its effect on performance, especially at altitudes familiar to GA pilots, but does not fulfill the purpose of this research, which is to gain hypoxia experience statistics from GA pilots.

Hypoxia is thought to be more of a risk for airline pilots, who receive regular training in recognizing the symptoms of hypoxia. This training is not required but is still provided due to the higher altitudes airline pilots use on a regular basis. During one transatlantic flight, an airliner experienced what is known as a "stuck valve," which causes a pressurization leak:

The cabin altitude reached between 15,000 and $20,000 \mathrm{ft}$ MSL (between 4572 and $6096 \mathrm{~m}$ ). The pilot in command had recognized the issue, donned his oxygen mask, and descended to below $10,000 \mathrm{ft}(3048 \mathrm{~m})$ as corrective action while the senior crew chief took over the emergency procedures checklist to resolve the valve malfunction (Coffey, 2014, para 3).

This study focused on pressurized aircraft, which would typically be airliners and jets that can fly at higher altitudes. The report then details how quickly the pilots can recover from various periods of time in a pressurization leak. This report highlights the fact that the pilot in this scenario was able to recognize his symptoms and don his oxygen mask, a luxury most GA pilots do not have. It is rare to find GA pilots using oxygen equipment, even though the majority of GA aircrafts can reach altitudes where performance is affected, as seen in the study of Nesthus et al. (1997).

It should also be noted that airline pilots receive simulation training on recognition of hypoxia symptoms, something that is not required or promoted in GA. While this report articulates the short amount of time pilots have to recover from a dangerous situation, it does not report the frequency of the event or techniques used to recover from the hypoxic event.

Since no form of flight physiology training is required for GA, it is rare to find a GA pilot that has taken a flight physiology course. Military physiological training is by far the most intense and comprehensive training compared to commercial and GA training. Regular hypobaric chamber training is required for all fixed-wing crewmembers: "The U.S. Air Force showed that $80 \%$ of pilots who had not received previous training required up to 15 seconds to don their oxygen masks. However, there was no comparison with those who did have previous training" (Johnston, Iremonger, Hunt, \& Beattie, 2012, p. 962). This study stresses the importance of previous training based on the reaction time of recognizing symptoms.

It is widely taught that experiences in a hypobaric chamber can help pilots recognize their own personal symptoms of hypoxia faster, which helps them react faster. Johnston et al. (2012) go on to say, "An analysis of reported hypoxia incidents in the Australian Defense Force from June 1990 through March 2001 revealed that $76 \%$ of cases were selfrecognized, while $10 \%$ were recognized by another crewmember, and 14\% were unrecognized" (p. 962). While most military flight activities involve more than one crewmember, GA pilots often fly solo, and therefore lack other crewmembers to recognize their hypoxic symptoms. Johnston et al.'s report articulates the twofold hazard that GA pilots face: single pilot resource management and inadequate flight physiology training, which lead to unrecognized symptoms of hypoxia during flight.

A similar military aviation study focuses on previous physiological training reaction and recognition versus acute experience. The study found that, "During acute hypoxia, $65 \%$ of aircrew experienced the five symptoms they remembered to be dominant from previous training; $57 \%$ of aircrew remembered from previous training the symptoms that dominated their experience of acute hypoxia" (Smith, 2008, p. 54). While this study amplifies a crucial point, it involves the use of military pilots with equipment that is readily available to them for training.

There are numerous studies showing how affected pilots can become hypoxic at altitudes familiar and seemingly "safe" to the GA community. One such study examined "how oxygen deprivation below 14,000 ft affects pilot performance....at simulated altitudes of 5,000 ft and 14,000 ft" (Shideler, 2012, p. iv). While studies such as this one focus on flight conditions familiar to GA pilots, they do not maintain any statistics detailing the level of experience or recognition of symptoms, a critical piece to this research.

Everyone in the aviation community has heard of deadly hypoxia-related accidents caused by pilot error or equipment malfunctions. However, rarely do they ever hear of pilots that survive the hypoxic event without incident. The aviation community does not even have records or statistics as to how often such physiological events occur. 
Without these statistics, the GA world has little knowledge of the common cause of hypoxia or how pilots can recover from it. One of the rare exceptions to these hypoxia survival stories is the flight of Kalitta KFS-66. En route from Manassas, Virginia to Detroit Willow Run Airport at 32,000 feet, "the primary controller Jay McCombs tried to understand, with the help of a second pilot in another aircraft, what the crew was reporting; his colleague Stephanie Bevins tuned the radio frequency and recognized that the crew was suffering from severe hypoxia" (Hradecky, 2010, para 1). With the help of Cleveland air traffic controllers, the flight was able to descend to 11,000 feet and land safely. Currently, there is little in the way of research or statistics about how pilots recover from hypoxia, whether they recover from their own recognition and action or with the assistance of another crewmember or air traffic control. Although Kalitta KFS-66 is a fitting example of a flight crew that survived a hypoxic event in normal flight operations, it is not safe to assume that air traffic control plays a role in helping pilots recover from hypoxia in every incident. In fact, many instances go unreported.

There may be many reasons why a pilot chooses not to report a hypoxic event:

1. Fear of retribution for lack of training.

2. Unsafe conditions that may have developed from their impairment.

3. Belief that a report is unnecessary since they survived the incident.

It is hard to determine the exact reasons why pilots choose not file a report, even an anonymous one. It is also hard to determine how often reports are filed because the data are confidential. Without these reports, the aviation community lacks a baseline of data to build mitigation and training to prevent more of these incidents from occurring.

\section{Methodology}

The target audience consisted of pilots who had experienced a hypoxic event during non-commercial flight operations. These individuals may have experience or hold a job in the commercial aviation industry, but at the time of the hypoxic event, they had been flying GA aircraft in notfor-hire operations. To reach the desired audience of GA pilots, researchers distributed the survey through the Aircraft Owners and Pilots Association (AOPA), an organization that has a well-known history of promoting general aviation, protecting private pilots' rights, and offering various safety courses. The survey was also distributed by Curt Lewis \& Associates, a safety organization that sends weekly emails to aviation industry professionals and enthusiasts regarding safety advancements and scholarly articles. A contact at the Airmen Certification Branch in Oklahoma City, however, informed the research team that distribution through the FAA would not be possible. The research team included a letter of explanation along with a link to the survey for AOPA email subscribers, as well as those subscribed to Curt Lewis \& Associates. AOPA has roughly 400,000 members, and roughly 36,000 people subscribe to Curt Lewis \& Associates. There were 344 total responses to the survey.

To obtain the most candid answers of the GA community about their experience with hypoxia, the research team drafted an anonymous survey consisting of 15 questions, shown in Table 1. To certify the most ethical practices in conducting the survey with informed consent, the primary researcher and faculty advisors completed training with the Collaborative Institutional Training Initiative (CITI). Once the CITI training was complete, the primary researcher then submitted an Institutional Review Board (IRB) application explaining the mission of the research, any potential risks to the human subjects involved, practices for safeguarding data, and a draft of the survey to be submitted, as well as an explanation of distribution methods. The IRB contacted the research team after two weeks with their letter of approval to carry out the survey. The researchers then created a survey using the Survey Monkey web-based software, which was distributed through the AOPA newsletter, Curt Lewis Enterprises, and social media.

The survey questions first asked if the participant had experienced hypoxia during normal non-commercial flight operations; if they answered no, the participant was routed to the final question, which was a free response question asking for suggestions regarding flight physiology training. This survey methodology allowed even those who had not experienced hypoxia to voice their opinions regarding flight physiology and training. The questions then queried respondents about their experience level as a pilot, including flight hours, certificates, and age at the time of the event. The survey also asked for specifics about the event, such as the aircraft's altitude, physical symptoms experienced, and whether they were the pilot in command at the time of the event. Lastly, participants were asked about any previous flight physiology training they may have had before the event and whether they reported the event. If participants did report the event, they were asked who they reported it to and what suggestions they have for future flight physiology training.

\section{Results of Study}

While not everyone will experience the same symptoms when they encounter hypoxia, there are a few symptoms that are commonly reported, such as lightheadedness, headaches, shortness of breath, dizziness, cyanosis (appendages turning blue or cyan), tunnel vision, and air hunger (rapid breathing due to low blood oxygen levels). Unfortunately, because hypoxia has at least four different causes, it is possible to experience hypoxia at any altitude. Out of the 200 respondents of the study, $15 \%$ of them experienced 
Table 1

Hypoxia survey questions provided through SurveyMonkey.com.

\begin{tabular}{|c|c|}
\hline Questions & Possible responses \\
\hline 1. Have you ever experienced a hypoxic event during normal flight operations? & Yes, No, Uncertain \\
\hline 2. If yes how long ago did the hypoxic event occur? & $\begin{array}{l}\text { Less than } 1 \text { year, } 1-5 \text { years, } 5-10 \text { years, } \\
10-20 \text { years, } 20-40 \text { years }\end{array}$ \\
\hline 3. What was your age when this hypoxic event happened? & $14-24,25-45,46-60,61-80,80+$ \\
\hline 4. At the time of the hypoxic event what was the highest pilot certificate you held? & Student, PPL, SEL, MEL, ATP \\
\hline 5. Approximately how many hours did you have at the time that the hypoxic event occurred? & $\begin{array}{l}10-500,500-1000,1000-5000,5000-10,000 \\
10,000+\end{array}$ \\
\hline 6. When you experienced this hypoxic event, which of the following aircraft was it in? & Rotary, Fixed-wing \\
\hline 7. What was the approximate altitude at which the hypoxic event occurred? & $\begin{array}{l}\text { 0-10,000MSL, 10,000-20,000MSL, } \\
\text { 20,000-40,000MSL, 40,000-50,000MSL }\end{array}$ \\
\hline $\begin{array}{l}\text { 8. a) Before the hypoxic event occurred, had you ever received flight physiology training } \\
\text { specific to hypoxia? }\end{array}$ & Yes, No \\
\hline 8. b) If yes, was it civilian or military training? & Civilian, Military, N/A \\
\hline $\begin{array}{l}\text { 8. c) If it was civilian training, did you attend the training on your own initiative, } \\
\text { or did your training program require it? }\end{array}$ & $\begin{array}{l}\text { Required by training program, My own } \\
\text { initiative, N/A }\end{array}$ \\
\hline 9. Before the hypoxic event occurred, had you ever received any high altitude training? & Yes, No \\
\hline 10. Were you acting as PIC at the time the hypoxic event occurred? & Yes, No \\
\hline $\begin{array}{l}\text { 11. Which of the following symptoms were you able to identify as hypoxia during this event? } \\
\text { (Check all that apply) }\end{array}$ & $\begin{array}{l}\text { Cyanosis, Shortness of breath, Euphoria, Tunnel } \\
\text { vision, Slowed muscle movement, Headache, } \\
\text { Blurred vision, Dizziness, Sleepiness, } \\
\text { Lightheadedness, Numbness, Tingling, Other }\end{array}$ \\
\hline $\begin{array}{l}\text { 12. Which of the following best answers this statement: "ATC played a significant role in } \\
\text { my recovery from the hypoxic event"? }\end{array}$ & $\begin{array}{l}\text { Strongly agree, Agree, Uncertain, Disagree, Strongly } \\
\text { disagree }\end{array}$ \\
\hline 13. Did you report this hypoxic event? & Yes, No \\
\hline 13. b) If so, to whom? & Answers vary \\
\hline 13. c) If not, what was your reasoning? & Answers vary \\
\hline 14. Did your hypoxic event cause an unsafe flight situation? & Yes, No \\
\hline 15. What suggestions do you have in regards to hypoxia training? & Answers vary \\
\hline
\end{tabular}

Table 2

Hypoxia symptoms below 10,000 feet.

\begin{tabular}{|c|c|c|c|c|c|c|c|c|}
\hline 10,000 feet or less & Reduced vision & Metal confusion & Dizziness & Sleepiness & Lightheadedness & Headache & Euphoria & Other \\
\hline \multicolumn{9}{|l|}{ Symptoms } \\
\hline (26 participants) & $11 \%$ & $36 \%$ & $23 \%$ & $16 \%$ & $39 \%$ & $16 \%$ & $13 \%$ & $42 \%$ \\
\hline
\end{tabular}

symptoms consistent with hypoxia at altitudes of 10,000 feet or below, where carriage of supplemental oxygen is not required by law. Of that $15 \%$, several pilots had specific responses about what they experienced. One commented that they "could not interpret the altimeter," while others reported sleepiness, blurred vision, and color vision deterioration.

These data show that, like the study done of pilots between 5,000 and 14,000 feet, pilots can experience symptoms of hypoxia that make controlling the aircraft more difficult. These symptoms are more harmful if one considers that GA pilots are presumably less experienced than are commercial pilots, as seen by the average survey demographic of 25-45 years of age, the average highest certificate being private pilot, and the average flying time being 1,000-5,000.

"Pilots must understand that the signs and symptoms of hypoxia are as varied and individual as the person experiencing them. Pilots who are hypoxic will experience (most of the time) similar signs and symptoms. However, the signs and symptoms may appear in a different order and in varying intensities" (Boshers, 2015, para 13).

There were no definitive trends that showed a relationship between altitude level and symptoms experienced, as seen in Tables 2 and 3, likely due to the various health histories and body sizes of the pilots surveyed. The category of "other" is a free response category that allowed participants to describe uncommon symptoms that did not fit the categories available, such as warming sensations, tingling, irritability, or anxiety. Seventy-two percent of participants reported their hypoxic event was encountered between 10,000 and 20,000 feet. This demonstrates that pilots can experience the detrimental effects of hypoxia at altitudes that are accessible to GA aircraft and at altitudes that do not legally require oxygen. 
Table 3

Hypoxia symptoms between 10,000 feet and 20,000 feet.

\begin{tabular}{lcccccccc}
\hline $\mathbf{1 0 , 0 0 0 - 2 0 , 0 0 0}$ feet & Reduced vision & Metal confusion & Dizziness & Sleepiness & Lightheadedness & Headache & Euphoria & Other \\
\hline Symptoms (130 participants) & $12 \%$ & $16 \%$ & $18 \%$ & $19 \%$ & $42 \%$ & $29 \%$ & $17 \%$ & $39 \%$ \\
\hline
\end{tabular}

Table 4

Reporting statistics for hypoxia occurrences.

10,000 Feet or less (out of 26 participants)

10,000-20,000 feet (out of 130 participants)

Did report

Did not report

With symptoms such as mental confusion and sleepiness, it is easy to see why the risk of pilot error can increase when experiencing hypoxia-like symptoms. Many may not even recognize what they are experiencing is hypoxia. Participants in this study were also asked if they reported their event to any recording agency or authority. Out of the 200 respondents, 94\% did not report their hypoxic event to a recording agency or authority. Of the $6 \%$ who did, the authority to whom they reported varied between air traffic control centers, flight instructors, and flight surgeons and medical examiners. This variation in reporting is likely because there is not a specifically designated reporting agency for flight physiology events and there is no legal requirement to report any such event.

As for the $94 \%$ that did not report their hypoxia, some of their reasons were that there was no requirement to report it, they did not recognize that it was hypoxia, and/or they recovered safely by descending or applying oxygen. One respondent reported that he/she was "not allowed to fly at high altitudes" and therefore feared retribution by reporting the event; two others claimed they were not acting as pilot in command and therefore felt it was not their place to report the event. There were two pilots who said they did not know how to report their experience. There was a small difference in the number who reported their hypoxia in a lower altitude condition than the 10,000 to 20,000 feet group, as seen in Table 4 . This could simply be because the pool of responses was larger for the 10,000 to 20,000 feet group. Had there been a way for these pilots to report their hypoxic event, statistics on frequency and symptoms compared with altitude and pilot experience could have shown trends of hypoxic experiences and provided insight for preventing hypoxia at altitudes significant to GA pilots.

Participants were asked if they had any previous hypoxia training, such as experience with hypobaric chambers, as mentioned in the military study that showed a significant reduction in recognition time for those who had previously experienced hypoxia. The average price to participate in one chamber ride is approximately $\$ 200$ and the free hypobaric chamber ride course, sponsored by the FAA in Oklahoma City, has a waiting list of at least six months.
In other words, a hypobaric chamber is not readily accessible to most pilots, particularly in GA. The military requirement to participate in hypobaric chamber training makes formal training more common among previous military members in GA. Out of the 78 participants that had completed a hypobaric chamber ride prior to their hypoxic event, 53\% had their chamber ride in the military. Pilots who had a civilian chamber ride were asked if they were required to participate by their training program or if they went on their own initiative. This question was designed to show if pilots found personal motivation in learning more about hypoxia. Out of the 69 participants who answered affirmative regarding civilian training, $83 \%$ went on their own initiative. This significance in personal motivation shows that despite the scarcity of required training of hypoxia, the GA community has an interest in bettering their understanding of the effects and severity of hypoxia. Perhaps if training devices were more readily available, more GA pilots would use them.

\section{Recommendations}

This study demonstrates that the GA community is curious about hypoxia but struggles to gain more knowledge due to lack of training devices such as the hypobaric chamber, along with lack of regulations requiring such training. These deficiencies most likely stem from the misconception that GA aircrafts are less likely to encounter altitudes susceptible to hypoxia. As seen in the data from this study, GA pilots experienced severe symptoms of hypoxia at altitudes of 10,000 feet or less. Even more alarming is the fact that acute hypoxia is happening to undertrained, unsuspecting pilots who may not recognize their symptoms as hypoxia.

The final question was a free response question open to everyone who took the survey, including those that had not experienced hypoxia. The question asked participants what suggestions they had in regard to hypoxia training. Out of the 243 responses, $10 \%$ said they wanted more availability of hypobaric chamber rides. This supports the conclusion that most of the GA population would likely do a hypobaric 
chamber ride if it was more available, especially since $83 \%$ of participants who had done a chamber ride said they did so of their own initiative. Almost $40 \%$ of responses suggested having pilots participate in at least one chamber ride in order to recognize their symptoms before certain high-altitude flights or earning higher certificates. Out of all the responses, the most common recommendation was to put an emphasis on or add to hypoxia training as well as highly recommend regular training, either annually or by certificate. Therefore, training tools such as hypobaric chamber rides and pulse oximeters should be made more readily available to help GA pilots better recognize symptoms of hypoxia.

The other major issue, besides the availability of training tools, is the absence of a singular reporting authority for flight physiology events. Of the $94 \%$ that did not report their hypoxic event, most claimed that it was not required and that they did not see the significance of reporting it. If a single reporting authority was advertised as an anonymous source, pilots would be more likely to report their experiences, which would lead to more data and research on hypoxia and related topics. Furthermore, results from the survey data show that $15 \%$ of pilots experienced hypoxia at lower altitudes where oxygen is not required, thus highlighting the need to educate GA pilots about the hazards of hypoxia.

Embry-Riddle Aeronautical University's Prescott campus, sitting at an elevation of over 5,000 feet, has a flight program utilizing GA aircrafts that sees hundreds of flights per day. With the large amount of flights conducted between 5,000 and 11,500 feet, the flight program at Embry-Riddle would be a prime data-logging point for hypoxia studies. Further research could be done on the student pilots of Embry-Riddle by having them carry pulse oximeters and monitor their performance data over a period of time. This research could provide insight into the effects of high-elevation flying, particularly the effects of this condition over time.

In addition to further study of hypoxia in GA aircraft, comparing and evaluating the effectiveness of current physiology training programs would provide valuable information. A new course or program could be outlined after comparing the preexisting programs.

\section{Conclusion}

This study shows that the perception that GA pilots are less susceptible to hypoxia is invalid, and if hypoxia training tools, such as hypobaric chambers, become more available, they would be put to significant use in the GA community. Additionally, the study found that pilots who experience hypoxia do not report their experience due to the absence of a single reporting authority and the lack of emphasis put on hypoxia in GA training. A change of attitude towards hypoxia in the GA community would help prevent future hypoxia-related accidents.

\section{References}

Boshers, L. (2015, July 21). Airman Education Programs. Retrieved September 21, 2016, from https://www.faa.gov/pilots/training/airman education/topics_of_interest/hypoxia/

Coffey, D. D. (2014). Unexplained hypoxia in an in-flight emergency. Aviation, Space, and Environmental Medicine, 85(6), 662-667. doi: 10.3357/asem.3850.2014

FAA. (2015, December 31). U.S. Civil Airmen Statistics. Retrieved November 22, 2016, from https://www.faa.gov/data_research/aviation_ data_statistics/civil_airmen_statistics

Hradecky, S. (2010, March 14). News: Cleveland air traffic controllers awarded for recognizing severe pilot's hypoxia, July 26, 2008. Retrieved September 21, 2016, from http://avherald.com/h?article= $428 \mathrm{a} 428 \mathrm{~b}$

Johnston, B. J., Iremonger, G. S., Hunt, S., \& Beattie, E. (2012). Hypoxia training: Symptom replication in experienced military aircrew. Aviation, Space, and Environmental Medicine, 83(10), 962-967. doi: 10.3357/asem.3172.2012

Nesthus, T. E., Rush, L. L., \& Wreggit, S. S. (1997, April). Effects of mild hypoxia on pilot performances at general aviation altitudes. Retrieved September 23, 2016, from http://www.faa.gov/data_research/research/ med_humanfacs/oamtechreports/1990s/media/am97-09.pdf

Shideler, D. F. (2012). Effects of oxygen deprivation on pilot performance and cognitive processing skills: A pilot study (order no. 1547944). Available from ProQuest Dissertations \& Theses Global. (1466003196). Retrieved from http://ezproxy2.plibproxy.pr.erau.edu/ login?url=http://search.proquest.com/docview/1466003196? accountid $=10734$

Smith, A. M. (2008). Hypoxia symptoms in military aircrew: Long-term recall vs. acute experience in training. Aviation, Space, and Environmental Medicine, 79(1), 54-57. doi: 10.3357/asem.2013.2008 